\title{
Incidencia del crédito de FUNDEMUJER en el desarrollo económico de MIPYMES en Estelí 1
}

\author{
Karen Alicia Rocha Galeano ${ }^{2}$ \\ Cristhiam Belén Valdivia Acuña ${ }^{3}$ \\ Francis Elieth Zeledón Lanuza ${ }^{4}$
}

1 Este artículo se basa en la investigación titulada Incidencia del crédito de FUNDEMUJER en el desarrollo económico de MIPYMES en Estelí. Para obtener el título de Licenciada en Administración de Empresas de la UNAN-Managua, FAREMEstelí.

2 UNAN-Managua FAREM-Estelí. Correo electrónico: kaliroch_24@yahoo.es

3 UNAN-Managua FAREM-Estelí. Correo electrónico: dlmusik7@gmail.com

4 UNAN-Managua FAREM-Estelí. Correo electrónico: franzela.sentimiento@gmail.com

\section{RESUMEN}

El presente trabajo determina la incidencia del crédito facilitado a mujeres, para el desarrollo económico de Micro, Pequeñas y Medianas Empresas en la ciudad de Estelí en el año 2013. El desarrollo de este estudio se hizo tomando en cuenta el enfoque cuantitativo. El universo de estudio fue de 434 mujeres empresarias que trabajan con crédito otorgados por la fundación con un tipo de muestreo probabilístico aleatorio simple, los instrumentos utilizados en el estudio fueron la encuesta y entrevista semi estructurada. Una limitante para el desarrollo económico de las empresarias es la falta de empleo existente en el país, esto hace que las mujeres recurran a solicitar créditos en entidades financieras, para poder crear sus negocios o mejorarlos.

Es fundamental que FUNDEMUJER realice capacitaciones sobre la importancia de establecer un sistema de registro contable en los negocios para conocer las utilidades que éste presenta y la importancia de invertir en publicidad para dar a conocer lo que se oferta, también promover el ahorro en las empresarias de tal forma que tengan un soporte para utilizarlo para algún imprevisto o bien para la inversión del negocio, y motivar a las empresarias a tener una visión positiva para el éxito del negocio.

Palabras claves: FUNDEMUJER, Crédito, Desarrollo económico, MIPYMES 


\title{
FUNDEMUJER credit impact on economic development of the MIPYMES in Estelí
}

\author{
Karen Alicia Rocha Galeano² \\ Cristhiam Belén Valdivia Acuña ${ }^{3}$ \\ Francis Elieth Zeledón Lanuza ${ }^{4}$
}

1 This article is based on the research titled FUNDEMUJER credit impact on economic development of the MIPYMES in Estelí. To obtain the title of Bachelor of Business Administration from the UNAN-Managua, FAREM-Estelí.

2 UNAN-Managua FAREM-Estelí. E-mail: kaliroch_24@yahoo.es

3 UNAN-Managua FAREM-Estelí. E-mail: dlmusik7@gmail.com

4 UNAN-Managua FAREM-Estelí. E-mail: franzela.sentimiento@gmail.com

\begin{abstract}
This study determined the incidence of credit provided to women, for the economic development of Micro, Small and Medium Enterprises in the city of Estelí in 2013. The development of this study was made taking into account the quantitative approach. The study group was 434 businesswomen working with credit granted by the foundation with a type of random probability sampling simple, the instruments used in the study were semi structured interview survey. A limiting factor for the economic development of women entrepreneurs is the lack of existing jobs in the country, this makes women to borrow in financial institutions, in order to create or improve their businesses.
\end{abstract}

It is essential that FUNDEMUJER perform training on the importance of establishing a system of accounting in business for profit and it shows the importance of investing in advertising to publicize what is offered, also promote the habit of savings in entrepreneurs so they have a support to use in case of unexpected situations or business investment, and motivate entrepreneurs to have a positive vision for business success.

Keywords: FUNDEMUJER, Credit, Economic Development, MIPYMES 


\section{INTRODUCCIÓN}

En Nicaragua las personas optan a un crédito en diferentes instituciones financieras, por muchos aspectos, unos solicitan crédito para invertir en un negocio o para solventar otras deudas, estas son personas que por circunstancias ajenas no han podido cumplir su compromiso en otras financieras y se ven obligados a adquirir otros créditos provocando así el sobreendeudamiento.

Las mujeres empresarias de la ciudad de Estelí que trabajan en sus propios negocios son de gran importancia para la economía, sin embargo, no cuentan con los suficientes recursos para ampliar y diversificar sus negocios, por esta razón solicitan créditos que difícilmente son aprobados porque no cuentan con ingresos fijos para solventar sus deudas.

El desarrollo de estos negocios enfrenta diversos obstáculos que impiden su crecimiento. Los principales obstáculos para el crecimiento de éstos es la falta de capital, por ende no habrá adquisición de productos para abastecer y ofrecerlos en el mercado.

En Estelí existen diferentes instituciones financieras que facilitan captación de ahorro y otorgamiento de créditos, pero presentan altas tasas de interés y muchos requisitos que complica el otorgamiento de créditos a las mujeres.

La Fundación para el Desarrollo de la Mujer FUNDEMUJER, es creada en respuesta a la desigualdad de género existente y para contribuir al empoderamiento económico y ciudadano de las mujeres empresarias Nicaragüenses.

Las mujeres empresarias tienen la iniciativa de crear sus negocios, puesto que su principal prioridad son sus hijos y sus familias. Cuando las mujeres deciden por solicitar un prestamos lo hacen para su beneficio aunque si no se asume con compromiso esa responsabilidad puede generar el sobreendeudamiento, y las instituciones financieras recurren a la cobranza por el tiempo de mora en el pago de las cuotas.

En otras ocasiones las mujeres han arriesgado sus bienes al no hacerse responsables de sus deudas, por que ponen en garantía lo que con tanto esfuerzo ha logrado obtener, y que en ocasiones hacen un mal uso del crédito, destinando ese dinero a la adquisición de bienes que no son de utilidad para el desarrollo de sus negocios.

Una limitante para el desarrollo económico de las microempresas es la falta de empleo existente en el país, esto hace que las mujeres recurran a solicitar créditos en entidades financieras, para poder crear sus negocios o mejorarlos, de esta manera promueven el desarrollo personal y familiar.

Obviamente la falta de empleo ocasiona la escases de capital y sin capital no hay inversión para el cual conlleva a expandir, innovar y diversificar un negocio aunque este traiga consigo riesgos al momento de invertir esto se produce cuando existe una mala administración y control de los recursos financieros con los que se cuenta puesto que la prioridad primordial simplemente es vender y obtener ingresos que les permitan sobrevivir y esta visión es por la que varios negocios han fracasado.

Además, cabe mencionar que si un negocio no cuenta con una buena administración difícilmente se conocerá lo que se tiene en inventario, por otro lado no se podrá conocer si el negocio está produciendo pérdidas o utilidades.

El presente trabajo investigativo tiene como objetivo primordial Determinar la Incidencia del crédito facilitado a las mujeres, por FUNDEMUJER para el desarrollo económico de Micro, Pequeñas y Medianas Empresas (MIPYME) en la ciudad de Estelí en el año 2013. 
La realización de este trabajo será de gran importancia para FUNDEMUJER ya que les servirá para conocer las dificultades que han presentado las empresarias con sus créditos, y de esta manera encontrar una salida que sea beneficiosa para ambas partes. Esta investigación, es un punto de partida para aquellas mujeres que iniciarán sus negocios ya que les proporcionara una información real, que hará que reduzcan riesgos económicos en sus negocios y podrán manejar con responsabilidad la administración de futuros créditos, además, esta información motivara a aquellas mujeres emprendedoras que aspiren a crear sus pequeños, medianos o grandes negocios para que les permitan tener un mejor nivel de vida.

\section{MATERIALES Y MÉTODOS}

Para llevar a cabo la realización de esta investigación se utilizaron fuentes primarias de carácter cuantitativo cuyo instrumento fueron encuestas semi estructurada a las propietarias de negocios donde se recopilo información acerca de las generalidades del negocio (antigüedad, tipo, número de empleados), la utilización de registros contables y otros temas de carácter cualitativo como la valoración de FUNDEMUJER por parte de las propietarias. Se aplicaron entrevistas aplicadas a la responsable administrativa licenciada Claudia María Montoya Gámez, a la gerente de crédito Licenciada Nubia Cruz Figueroa a un promotor de crédito Sr Wilmer Ramón Gonzales y a diez empresarias de la ciudad de Estelí. También se hizo una búsqueda bibliográfica de diferentes libros, informes, revistas, trabajos de curso y páginas web para enriquecer la información obtenida durante esta investigación.

\section{RESULTADOS Y DISCUSIÓN}

Descripción de la Fundación para el Desarrollo de la Mujer FUNDEMUJER
La Fundación para el Desarrollo de la Mujer (FUNDEMUJER), es una asociación sin fines de lucro. Nació en el año 2002, como una institución dedicada a la prestación de servicios no financieros tales como: capacitación, organización, asistencia técnica, acciones afirmativas de género y empoderamiento a las microempresarias del departamento del norte de Nicaragua.

En el año 2006 producto de la dinámica propia, y siempre con la visión de crear espacios y opciones que complementasen de forma más efectiva las posibilidades de mejoría que contribuyesen a la independencia económica de la mujer, las personas creadoras de FUNDEMUJER, consideraron necesaria la conformación de una entidad que, trabajando paralela y complementariamente, se encargarse de facilitar los servicios de crédito a las mujeres, operando con enfoque empresarial y en condiciones de mercado, de modo a asegurar la autosostenibilidad en el menor tiempo posible y el nivel de crecimiento que permitiese fortalecer la situación patrimonial de la nueva entidad.

Después de haber pasado por una etapa inicial, en que la conformación de la Junta Directiva, se asume el compromiso de acompañar a la mujeres en el proceso integral de empoderamiento económico y social, se produjeron reformas estatutarias que eliminaron esa restricción, pero que a la vez estableció el predominio del enfoque de género o de igualdad de oportunidades en el actuar de la institución.

La Personería jurídica se aprobó en el mes de noviembre del año 2007, según decreto número 5245 de otorgamiento de personería jurídica publicado en La gaceta, diario oficial número 228 .

FUNDEMUJER, tiene su sede central en la ciudad de Estelí y cuenta con una sucursal en la ciudad de Sebáco y en la ciudad de Condega desde estas oficinas atiende los municipios de: La Trinidad, Limay, Ciudad Darío y Matagalpa. 


\section{Enfoque de Género}

La Fundación para el desarrollo de la mujer FUNDEMUJER, es una micro financiera cuyo eje social está enfocado al empoderamiento de las mujeres empresarias que llevan el sustento a sus hogares mediante sus negocios, siendo ellas mujeres responsables con sus créditos y demostrando que son excelentes administradoras con los ingresos y egresos de su giro comercial, ya que son más detallistas al momento de llevar el control de inversiones sobre sus negocios por muy pequeños que estos sean.

Otro de los factores incluido como parte de la misión de FUNDEMUJER, es el fortalecimiento de las mujeres en la incidencia de las gestiones públicas en los diferentes niveles sociales, ubicando a la mujer como parte elemental de dichas gestiones ya que son ellas capaces de contribuir al desarrollo comunitario.

Sin embargo, los hombres son caracterizados por ser fuertes e independientes, en FUNDEMUJER pueden optar a los créditos pero en un mínimo porcentaje, ya que ellos están respaldados por otras instituciones financieras, sobre todo cuando desarrollan labores del campo o la ciudad y cuentan con un cargo en alguna institución. Pero las mujeres empresaria solo cuentan con el apoyo y seguimiento de las micro financiera que destinan créditos preferenciales a su capacidad administrativa.

Se toman en cuenta las diferencias en el desempeño empresarial de hombres y mujeres y consideran los factores de género que influyen de manera particular en la función empresarial y la competitividad de las mujeres los que, en muchos casos, pueden limitar su rol.

No son iguales las condiciones de un hombre empresario, que sólo realiza el trabajo productivo y las condiciones de una mujer empresaria quien, además del trabajo productivo, realiza el trabajo doméstico o reproductivo.
Las mujeres han enfrentado inequidad en diversos ámbitos, entre ellos el económico. Se ha asumido la responsabilidad de promover la igualdad de oportunidades y fomentar el empoderamiento de las mujeres para que gocen plenamente de sus derechos y libertades sin discriminación ni exclusión.

La búsqueda de la igualdad de género es un elemento central de una visión de la sostenibilidad en la cual cada miembro de la sociedad respeta a los demás y desempeña un papel que le permite aprovechar su potencial al máximo. La amplia meta de la igualdad de género es una meta social a la que la educación y las demás instituciones sociales deben contribuir. La discriminación de género está imbricada en el tejido de las sociedades. En muchas sociedades, las mujeres llevan la carga principal de la producción de alimentos y la crianza de los niños. Además, las mujeres a menudo son excluidas de las decisiones familiares o comunitarias que afectan a sus vidas y bienestar.

La participación total y equitativa de las mujeres es vital para asegurar un futuro sostenible porque: los roles de género son creados por la sociedad y se aprenden de una generación a otra; los roles de género son constructos sociales y se pueden cambiar para alcanzar la igualdad y la equidad entre las mujeres y los hombres; empoderar a las mujeres es una herramienta indispensable para hacer avanzar el desarrollo y reducir la pobreza; las desigualdades de género socavan la capacidad de las niñas y mujeres de ejercer sus derechos; asegurar la igualdad de género entre niños y niñas significa que ambos tienen las mismas oportunidades para acceder a la escuela, así como durante el transcurso de sus estudios.

\section{Descripción del Programa de Crédito y Proyectos de FUNDEMUJER}

La Fundación para el desarrollo de la mujer pretende llegar a mujeres que tienen menos acceso al crédito 
convencional y apoyar el desarrollo de sus iniciativas económicas. Las actividades que financia estan enfocados en el sector servicio, producción, comercio, ganadería, agropecuario, y personales.

El monto mínimo que se aprueba es de U\$100.00 dólares y máximo de U\$8,000.00 dólares. La modalidad de pago es mensual, trimestral, semestral o al vencimiento. La garantía que se solicita depende del monto del crédito, pueden ser: fiduciarias, prendarias, o hipotecaria.

La documentación requerida son: copia de cedula, matricula del negocio, factura de compra, recibo de remesas, pensiones, alquiler de casa, copia de colilla del INSS, recibo de servicios básicos, reporte de sin riesgo, formato de garantías, en caso de hipoteca, escritura pública, libertad de gravamen, solvencia municipal, avaluó, tener un año el negocio y el fiador como mínimo un año como de trabajar.

La Tasa de Morosidad es de $1.30 \%$ puesto que se ha presentado excelente participación por parte de las empresarias que en este sentido son a 434 mujeres que actualmente tienen créditos aprobados.

Manejo y control de cartera

Por políticas internas, por cada crédito se mantiene un monto mínimo y máximo de aprobación, esto está en dependencia en la actividad económica a la que se dediquen, de igual forma la modalidad de pago. (Véase cuadro 2)

\begin{tabular}{|c|c|c|c|c|c|c|}
\hline Crédito & Producción & Servicio & Comercio & Agropecuaria & Ganadería & Personal \\
\hline Monto Mínimo & $\$ 100.00$ & $\$ 100.00$ & $\$ 100.00$ & $\$ 1,000.00$ & $\$ 1,000.00$ & $\$ 200.00$ \\
\hline Monto Máximo & $\$ 8,000.00$ & $\$ 8,000.00$ & $\$ 8,000.00$ & $\$ 8,000.00$ & $\$ 8,000.00$ & $\$ 1,500.00$ \\
\hline $\begin{array}{l}\text { Tasa de interés } \\
\text { Nominal }\end{array}$ & $1.5 \%$ & $1.5 \%$ & $1.5 \%$ & $1.5 \%$ & $1.5 \%$ & $1.5 \%$ \\
\hline $\begin{array}{l}\text { Plazos mínimos } \\
\text { por actividad }\end{array}$ & 4 a 18 meses & 4 a 18 meses & 4 a 18 meses & 6 a 24 meses & 6 a 24 meses & 6 a 12 meses \\
\hline $\begin{array}{l}\text { Modalidad de } \\
\text { pago }\end{array}$ & $\begin{array}{l}\text { Quincenal o } \\
\text { Mensual }\end{array}$ & $\begin{array}{l}\text { Quincenal o } \\
\text { Mensual }\end{array}$ & $\begin{array}{l}\text { Quincenal o } \\
\text { Mensual }\end{array}$ & $\begin{array}{l}\text { Trimestral, } \\
\text { Semestral o al } \\
\text { Vencimiento }\end{array}$ & $\begin{array}{l}\text { Trimestral, } \\
\text { Semestral o al } \\
\text { Vencimiento }\end{array}$ & Mensual \\
\hline $\begin{array}{l}\text { Garantía por } \\
\text { actividad }\end{array}$ & $\begin{array}{l}\text { Fiador, } \\
\text { Prendaria, } \\
\text { Hipotecaria / } \\
\text { Combinación }\end{array}$ & $\begin{array}{l}\text { Fiador, } \\
\text { Prendaria, } \\
\text { Hipotecaria / } \\
\text { Combinación }\end{array}$ & $\begin{array}{l}\text { Fiador, } \\
\text { Prendaria, } \\
\text { Hipotecaria / } \\
\text { Combinación }\end{array}$ & $\begin{array}{l}\text { Carta de venta, } \\
\text { Hipotecaria }\end{array}$ & $\begin{array}{l}\text { Carta de venta, } \\
\text { Hipotecaria }\end{array}$ & $\begin{array}{l}\text { Fiador, } \\
\text { Prendaria, } \\
\text { Hipotecaria / } \\
\text { Combinación }\end{array}$ \\
\hline
\end{tabular}

Cuadro $\mathrm{N}^{\circ} 1$. Manejo y Control de cartera de FUNDEMUJER

Periodo: Primer semestre 2013. Fuente: FUNDEMUJER

Durante los años 2011 se presentó una cartera de crédito $\mathrm{C} \$ 362,500$ donde se contaba con poca participación de clientes, para el año 2012 tuvo un aumento con $C \$ 1.450,000$, esto quiere decir, que la cartera ha aumentado considerablemente en un $25 \%$ por cada año, puesto que se han presentado una constante participación por parte de las mujeres, y la reestructuración de los mismos ha sido continua.

Según información de la Gerente de Crédito, en el primer semestre 2013, FUNDEMUJER cuenta con una cartera de préstamo de $C \$ 5,800,000$ córdobas netos ya que la participación en la clientela incrementa cada vez más.

El número de clientes con los que actualmente se cuenta es de 434 aprobaciones de créditos a mujeres, se cuenta con 520 préstamos desembolsados acumulados.

El crecimiento porcentual de cartera es de $6 \%$ mensual, y la cartera en mora es del $2 \%$, esto es muy satisfactorio puesto que las mujeres responden bien ante la deuda y los pagos correspondientes. 
El monto de colocación por periodo mensual es de C\$1, 200,000 córdobas netos y el monto de recuperación por ese periodo es de $\mathrm{C} \$ 1,000,00$ al mes. Actualmente la estructura de cartera por sector tiene una variación porcentual en relación al sector comercio del que se dedica entre estos se destacan los siguientes (Véase cuadro No.2):

\begin{tabular}{|l|l|}
\hline Sector Económico & $\begin{array}{l}\text { Porcentaje } \\
\text { (primer semestre 2013) }\end{array}$ \\
\hline Comercio & $65 \%$ \\
\hline Servicio & $5 \%$ \\
\hline Agropecuario & $12 \%$ \\
\hline Personal & $1 \%$ \\
\hline Ganadero & $12 \%$ \\
\hline Pequeña industria & $5 \%$ \\
\hline TOTAL & $\mathbf{1 0 0 \%}$ \\
\hline
\end{tabular}

Cuadro $\mathrm{N}^{\circ}$ 2. Estructura de Cartera por sector primer semestre 2013. Fuente: FUNDEMUJER

El $65 \%$ de la cartera de crédito está enfocada al sector comercio puesto que las empresarias tienen negocios fijos dentro de la ciudad de Estelí y por lo general son negocios de servicio y venta de bienes.

En cuanto a los gastos, las empresarias realizan los pagos para la utilización del servicio sin recibir ningún tipo de deducciones con el préstamo solicitado, los pagos los realizan por separado.

\section{Proyecto de Jóvenes}

FUNDEMUJER a inicio del año 2012 ejecuta el proyecto dirigido a jóvenes denominado: Inclusión y empoderamiento ciudadano de las/los jóvenes del municipio de Condega en el marco de la planificación y gestión pública.

El objetivo de este proyecto es contribuir al mejoramiento de las condiciones de vida de las/los adolescentes y jóvenes del municipio de Condega mediante la dotación de herramientas de gestión pública e inclusión efectiva en los espacios de participación ciudadana que les permita empoderarse de los marcos jurídicos y el pleno ejercicio de sus derechos.

Este proyecto consiste en la participación ciudadana, brindando capacitación a adolescentes y jóvenes sobre el marco jurídico, entre las principales temáticas se encuentran, ley de municipios, ley 392 participación ciudadana (promoción y desarrollo integral de la juventud), ley 763 personas con discapacidad.

Entre los resultados esperados se encuentran:

- Presentar una agenda joven al consejo municipal de Condega donde se recopila el problema que tiene la juventud actualmente.

- Formar un consejo municipal de adolescentes y jóvenes reglamental entre consejos.

- Formar mesas temáticas de interés juvenil como: empleo educación recreación, producción y cultura.

Este proyecto incide directamente en 35 jóvenes e indirectamente alrededor de 600 adolescentes y jóvenes. Se trabaja en coordinación con MINSA, MINED, COOPERATIVA (CENDERO DE LICOROY), es ejecutado por FUNDEMUJER en alianza con la casa de adolescentes y jóvenes del municipio de Condega.

Así mismo, en coordinación con FGD Fondo de Gobernabilidad Democrática; este Programa es una iniciativa conjunta impulsada por la Embajada de la República Federal de Alemania, la Embajada del Reino de los Países Bajos, la Agencia Suiza para el Desarrollo y la Cooperación (COSUDE), la Embajada de Finlandia y la Embajada del Gran Ducado de Luxemburgo, para apoyar a la Sociedad Civil nicaragüense para contribuir a la Gobernabilidad Democrática en el país.

La función de Unidad Ejecutora ha sido asignada a IBIS Dinamarca, Agencia de Cooperación Internacional, 
quien tiene bajo su responsabilidad la administración eficiente del Programa y la asistencia técnica a las organizaciones de la sociedad civil interesadas en la ejecución de proyectos vinculados a esta iniciativa.

El Fondo de Gobernabilidad Democrática pretende apoyar los esfuerzos que Nicaragua viene realizando en sus procesos de democratización, institucionalización y participación ciudadana y se orienta a fortalecer las capacidades de las organizaciones y redes de la Sociedad Civil en su proceso de diálogo e interacción con actores públicos y privados desde una visión propositiva y constructiva, en la búsqueda de aportar al desarrollo del país

\section{Caracterización de las propietarias y sus negocios que participan en el programa de crédito de FUNDEMUJER}

\section{Datos Generales de las Propietarias}

Las propietarias que han sido beneficiadas con créditos de FUNDEMUJER son el $50 \%$ mujeres en edades de 41 años, estas son las que presentan mayor rango de edad puesto de que alguna de estas mujeres no poseen un empleo y consideran que es mejor tener un negocio propio y ser independientes.

Se presenta un número muy reducido de mujeres en edades de 61 años a 70 años, con un $4 \%$ del total de las mujeres encuestadas, catalogadas como personas de tercera edad, estas son mujeres que tiene un negocio pero que por su edad pueden tener dificultad de pago y/o algún otro inconveniente y han optado por hacerlo en FUNDEMUJER puesto que en esta entidad no está establecido hasta que edad pueden tener un crédito.

Se presenta un porcentaje del $12 \%$ para mujeres comprendido en los rangos de 20 a 30 años, estas son mujeres que están en edad de desarrollarse ampliamente en el trabajo comercial puesto que pueden tener la posibilidad de ampliar sus negocios en el transcurrir de los años.
En relación al estado civil se puede observar que un $44 \%$ de las mujeres encuestadas son mujeres solteras, y por lo general mayores de edad, estas son mujeres independiente, que juegan el papel de padre y madre en sus hogares y saben manejar muy bien el negocio y tienen iniciativa de mantener fijo al mismo.

Un $43 \%$ de este universo de estudio presenta que las propietarias son casadas y optan por un crédito por diferentes razones una de ellas porque no quieren depender tanto de sus parejas o desean tener un negocio por cuenta propias.

Solamente, un $13 \%$ de las mujeres encuestadas son mujeres en uniones de hecho estables o acompañadas, representando el menor número de este universo de estudio. Estas mujeres tienen similares razones a las mujeres casadas con la diferencia que estas no están legalmente casadas, pero igualmente salen adelante por su cuenta.

Las mujeres propietarias de negocios de la ciudad de Estelí, son mujeres que por lo general no han concluido sus estudios de educación.

El $40 \%$ de las mujeres encuestadas solamente cursaron la primaria y pudieron aprender lo básico para poder manejar el negocio, algunas limitantes que se presentaron en el transcurso de los años es que por la economía y escases de empleos no podían ir a una escuela, puesto que era más importante trabajar y sustentar la familia que dedicar tiempo a la escuela.

El 4\% no lograron ingresar a una escuela y que en ocasiones solamente fueron orientadas o alfabetizadas por miembros de la familia no por instituciones o docentes.

También, se presenta un número considerable de mujeres que cursaron la secundaria reflejando el $31 \%$ del universo de estudio, estas mujeres han tenido la oportunidad de avanzar sus ciclos académicos puesto 
que las generaciones de antes se limitaban a las generaciones actuales. Un $8 \%$ representan mujeres que tuvieron estudios técnicos, como: secretariado, técnico en caja y un $17 \%$ que son mujeres universitarias estas mujeres han culminado los estudios permitiendo tener un amplio conocimiento teórico en cuestiones de toma de decisiones.

\section{Características generales de los negocios de las propietarias.}

Según las encuestas que se realizaron se demuestra que el $87 \%$ de las mujeres respondió que el establecimiento de su negocio es propio, esto es un beneficio agregado ya que no tiene que gastar en alquiler y pueden dar continuidad a su negocio desde la comodidad de sus hogares, el $12.25 \%$ renta el local estas por otra parte no gozan con un lugar propio por lo que corren riesgos como no tener dinero para pagar y desalojen el local y por ende perder la clientela que ya tienen ganada en su establecimiento y un $0.98 \%$ tiene su negocio establecido donde un familiar estas no pagan alquiler pero si corren el riesgo de que por algún motivo no les permitan continuar con el negocio en ese local y de igual manera pierdan a su clientela.

\section{Tipo de Negocio}

En cuanto a los tipos de negocios que se pudieron analizar en las encuestas y al totalizarlas se arrojaron datos y se seleccionaron los negocios más comunes como lo son las pulperías siendo los principales negocios ocupando un $49 \%$ del total de las encuestas realizadas, por lo general son pulperías puesto que es un negocio que a pesar de la competencia es muy demandado para satisfacer las necesidades de la población en general.

Un 13\% representan fritanga aunque cabe recalcar que en la casilla de fritanga se toma en cuenta todo tipo de Comideria como las ventas de nacatamales, panaderías, y un $16 \%$ representa la venta de ropa nueva y usada puesto que generaliza la venta de ropa, una porcentaje del $5 \%$ representan los servicios como salones de belleza, ciberes, manualidades, alquiler de sillas e inclusive barberías.

Las propietarias también tiene negocios ambulantes, como venta de $\mathrm{CD}$, controles, cosméticos e incluso ventas de comida, y consideran que es mejor ir a la calle a vender que tenerlo en un lugar estable porque no genera mucha ganancia.

El negocio de tortillería ocupa el $5 \%$ de las mujeres encuestadas que solamente se dedican a esta actividad porque consideran que es indispensable en la alimentación de las familias nicaragüenses y que pueden venderlo desde su hogar. Un 5.40\% son negocio poco comunes y no muy repetitivo en la realización de las encuestas estos son negocio de viveros, talleres de costura, venta de leche y artesanías.

\begin{tabular}{|l|l|l|}
\hline Nombre del comercio & Frecuencia & Porcentaje \\
\hline $\mathrm{Si}$ & 54 & $26.47 \%$ \\
\hline No & 150 & $73.53 \%$ \\
\hline TOTAL & 204 & $100 \%$ \\
\hline
\end{tabular}

Cuadro $\mathrm{N}^{\circ}$ 3. Nombre del negocio

Universo 204 encuestas.

Fuente: Datos Primaros de la Encuesta, Junio 2013

\section{Antigüedad del negocio}

El $33 \%$ de los negocios de las empresarias encuestadas presentan de seis a diez años esto quiere decir, que se encuentran muy bien posicionado en el mercado. Un porcentaje del 10\% tienen menos de dos años de estar operando en el mercado, esto quiere decir, que están iniciando sus actividades comerciales y sobre todo trabajando con el programa de crédito de FUNDEMUJER.

Un porcentaje del $30 \%$ indica que son negocios que tiene más de once años de estar a disposición de la clientela Esteliana esto indica que son negocios que 
van de generación tras generación por parte de sus familias.

\section{Características administrativas de los negocios de las propietarias}

\section{Inicio del Negocio}

El $66 \%$ de las mujeres encuestadas del total del universo de estudio afirman que el negocio inicio con capital propio, proporcionando una idea nueva de generar ingresos por cuenta propia.

El $30 \%$ afirma que el negocio inicio con capital prestado, esto lo iniciaron en diferentes instituciones financieras y una de estas instituciones es la fundación FUNDEMUJER que les proporciona la oportunidad de ampliar e invertir en los negocios, un $4 \%$ indica que se iniciaron los negocios por préstamos familiares puesto que en algunas ocasiones están ligados con la familias y es una estrategia que permite que la familia esté involucrada en la iniciativa de generar ingresos por medio de un negocio y que ellos mismos colaboren para el desarrollo de estos.

\section{Propósito del Negocio}

Existen diferentes alternativas que se toman en cuenta al momento de iniciar un negocio y parámetros por los cuales las mujeres deciden hacerlo, muchas de ellas lo hacen para sobrevivir siendo la mayoría con el $77 \%$ lo cual refleja que estas mujeres son las que llevan el sustento o parte de estos a sus hogares, y poder tener pan en sus mesas para la familia, más cuando estas mujeres son solteras, reflejando en este estudio que son la mayoría con un $44 \%$ del total encuestado.

El $19 \%$ optan por un negocio porque desean ingresos extras ya que aparte de las ganancias que generan de estos, tienen la facilidad de contar con otros recursos personales. Un $4 \%$ tiene ese negocio puesto que son encargadas del mismo ya que en algunas ocasiones los dueños del negocio son miembros de la, misma familia y se encuentran fuera del país, y ellas tienen el control del negocio mientras tanto.

\section{Número de trabajadores}

En los negocios de las mujeres encuestadas afirman que cuentan con poco personal trabajando en el negocio representando el $94 \%$ de los mismos que cuentan con uno a 5 trabajadores operando en los mismos dado que estos por lo general son pulperías (ver cuadro 5 tipos de negocios) y en las pulperías no es necesario tener el gran número de empleados y por lo general son miembros de la familia quienes trabajan en estas.

El 6\% indica que cuentan con un número de seis a treinta trabajadores operando en sus negocios puesto que según la clasificación de las MIPYMES están catalogadas como pequeñas empresas que cuentan de seis a treinta trabajadores.

\section{Publicidad}

\begin{tabular}{|l|l|l|}
\hline Publicidad & Frecuencia & Porcentaje \\
\hline Radial & 11 & $5.39 \%$ \\
\hline Televisiva & 0 & $0 \%$ \\
\hline Cliente a cliente & 97 & $47.55 \%$ \\
\hline Volantes & 2 & $0.98 \%$ \\
\hline ROTULO & 29 & $14.22 \%$ \\
\hline Revistas & 2 & $0.98 \%$ \\
\hline Ninguna & 63 & $30.88 \%$ \\
\hline TOTAL & $\mathbf{2 0 4}$ & $\mathbf{1 0 0} \%$ \\
\hline
\end{tabular}

Cuadro $\mathrm{N}^{\circ} 4$. Publicidad

Universo: 204 encuestas

Fuente: Datos de la Encuesta, Junio 2013 


\section{Crédito a Clientes}

Las empresarias conceden crédito a sus clientes por diferentes razones. Del total del universo de estudio se demuestra que el $72 \%$ concede crédito, puesto que consideran que es una buena forma de atraer clientela, y conservarla.

La mujeres que conceden crédito a sus clientes tienen riesgo a disminuir sus ganancias mensuales, puesto que cuando se presentan dificultades del no pago por parte de la clientela esto hace que disminuya las ganancias que genera el negocio ocasionada por la deuda de sus propios clientes.

El $28 \%$ de las propietarias no conceden crédito a los clientes puesto que, consideran que no es beneficioso hacerlo, porque se acumula el número de clientes y trae consigo la penosa cobranza y a los clientes no les gusta. Ellas consideran que dar crédito es complicado porque no es confiable y dar un voto de confianza de ese tipo no es para cualquier persona.

Inclusive, las personas utilizan rótulos con frases donde reflejan que en su negocio no se da crédito:

"Hoy no se fía, mañana si"

"Solo se fía a personas mayores de 90 años acompañados de sus abuelitos"

\section{Parámetros para otorgar crédito}

En relación al $72 \%$ de las mujeres encuestadas que otorgan crédito a sus clientes (ver cuadro 12. Crédito a clientes), se muestra que seden el crédito a la clientela por ser amistades con un $60 \%$ del total de las personas encuestadas, puesto que consideran que son de confianza y buena paga.

Un 38\% brindan el crédito a los clientes por el hecho de ser cliente porque de esta manera, los mantienen fijos, además pagan en tiempo y forma y son confiables .

\section{Registro de Crédito}

De las mujeres empresarias el $72 \%$ que conceden crédito, afirman que el $70 \%$ del total de las propietarias encuestadas anotan las cuentas de los clientes en un cuaderno, puesto que es una manera fácil y económica pero poco segura. Además, dicen que así como ellas las anotan los clientes también lo hacen y al momento de cancelar únicamente rayan la hoja y continúan la página y ambas partes hacen el mismo procedimiento anota, abona y cancela en el cuaderno todo por escrito.

Otro grupo de empresarias no lo consideran importante por eso, el $27 \%$ no anota la cuenta de sus clientes, dado que conocen al cliente y manejan el monto de su deuda y solamente el $1 \%$ registra en computadoras, ya que cuentan con el acceso a la utilización de la misma.

\section{Visión Futura}

Al realizar las encuestas al universo de estudio, se puede observar que el $87 \%$ tienen una visión positiva sobre su negocio asegurando que su negocio será más grande dentro de 5 años, sin embrago, un $11 \%$ no mira cambios en su negocio así que para el futuro lo miran igual, debido a que muchas mujeres miran su negocio de una forma pesimista, sólo como un medio para sobrevivir y no como algo que le deje buenas utilidades.

En esta actitud incide la edad de las propietarias quienes dice: "ya estoy muy cansada para continuar con el negocio" a tal punto que un $2 \%$ considera que su negocio estará cerrado dentro de un periodo no muy lejano. 


\section{Cumplimiento de la visión en cinco años}

\begin{tabular}{|l|l|l|}
\hline Visión a 5 años & Frecuencia & Porcentual \\
\hline Precios bajos & 171 & $83.82 \%$ \\
\hline Buena Atención & 123 & $60.29 \%$ \\
\hline Publicidad & 107 & $52.45 \%$ \\
\hline Hace rebajas & 98 & $48.04 \%$ \\
\hline Realiza promociones & 112 & $54.90 \%$ \\
\hline
\end{tabular}

Cuadro $\mathrm{N}^{\circ} 5$. Cumplimiento de la Visión en 5 años

Universo: 204.

Fuente: Datos de la Encuesta, Junio 2013

Ventajas y limitantes empresariales de las mipymes que tienen crédito de FUNDEMUJER

\section{Valoración del acceso a los préstamos en FUNDEMUJER}

Los montos promedios de aprobación para estas empresarias abarcan hasta los treinta mil córdobas, observando que con un porcentaje del $51 \%$ de estas mujeres solicitan montos mínimos, esto se debe a los bajos ingresos que ellas reciben, sin arriesgar sus ganancias lo cual les asegura el sustento de sus familias.

El 34\% toman la decisión de solicitar sus créditos por más de diez mil córdobas asumiendo así un poco más de seguridad en los ingresos recibidos por ellas y las ganancias que giran en torno a sus negocios.

Un 14\% del universo encuestado afirman que pueden asumir un crédito de más de veinte mil córdobas, con ello demostrando que pueden cubrir esta deuda un poco más simbólica, asegurando por tanto el buen control de sus movimientos de inversión a sus negocios y la actividad comercial a la que se dediquen, no obstante el mínimo porcentaje de estas mujeres correspondiente al restante del universo de estudio el cual $1.47 \%$ pueden sobre llevar un crédito igual o mayor a treinta mil córdobas, esto quiere decir, que sus negocios ya tienen una base sólida que genera utilidad en sus negocios y así poder potencializarlos sin que eso les proporcione riesgos sino ventajas en un ámbito competitivo, además la mayoría de los créditos son pagados en un plazo de 6 meses a un año o sino bien al vencimiento, y por lo general tarda hasta tres días para recibir el desembolso.

En la determinación de la aprobación de los créditos, FUNDEMUJER tiene que evaluar y llevar un proceso de control sobre el consentimiento de aprobación del crédito.

\section{Aprobación del Crédito}

El número de créditos aprobados completamente a las empresarias corresponden a un $92 \%$ un porcentaje que determina la aprobación de los créditos a las mujeres ya que son generadoras de ingresos de sus hogares, independientemente que estas reciban el total del crédito solicitado, no obstante hay un mínimo porcentaje de desaprobación que corresponde al $8 \%$ ya que existe un factor determinante que impide la confirmación del crédito completo solicitado, dicho factor se puede atribuir a la falta de documentación que es parte del proceso de requerimiento, el historial crediticio, o algún otro tipo de requisito que no es satisfactoriamente cumplido.

\section{Reestructuración del Crédito}

\begin{tabular}{|l|l|l|}
\hline Restructuración de Crédito & Frecuencia & Porcentaje \\
\hline $\mathrm{Si}$ & 165 & $80.88 \%$ \\
\hline No & 39 & $19.12 \%$ \\
\hline TOTAL & $\mathbf{2 0 4}$ & $\mathbf{1 0 0} \%$ \\
\hline
\end{tabular}

Cuadro $\mathrm{N}^{\circ}$ 6. Restructuración de crédito Universo: 204 encuestas

Fuente: Datos de la Encuesta, Junio 2013

\section{Aspectos que caracterizan a FUNDEMUJER}

Los aspectos más relevantes en cuanto a las atenciones que caracterizan a FUNDEMUJER son; la buena atención al cliente con un $77 \%$ de las mujeres se sienten muy bien atendidas por el personal que 
labora en esta prestigiosa institución financiera, además el $87 \%$ aseguran que este personal es amable y cortés desde la entrada al momento de solicitar atención o para realizar sus debidos pagos, en cuanto a la imagen de las instalaciones sólo un $48 \%$ se siente agusto con las instalaciones por su acogedor ambiente, espacio y sobre todo donde se encuentran ubicados. Algunas mujeres piensan que el espacio es muy pequeño, y en lo que respecta al seguimiento que FUNDEMUJER facilita a estas empresarias un $96 \%$ de las mujeres se siente muy satisfechas con ello puesto que consideran que reciben una atención especial después de recibido el crédito.

\section{Ventajas empresariales de las MIPYMES que tienen crédito en FUNDEMUJER}

Las propietarias presentan ventajas al obtener un crédito en FUNDEMUJER, esto les permite tener mayor crecimiento tanto personal, familiar como en los negocios para ampliarlos y diversificarlos.

Una de las principales ventajas es el aumento en ganancias presentadas en los negocios. De conformidad al análisis de las encuestas, el $43 \%$ de los negocios generan ganancias entre los mil y cinco mil cordobas mensuales. Un 33\% las generan hasta de diez mil córdobas puestos que algunos negocios son amplios y los productos o servicios que ofrecen son variados, por ende genera mayor utilidades, asi mismo un $2 . \%$ de los negocios obtienen utilidades hasta dequince mil cordobas porque algunas propietarias tienen más de un negocio.

Un $20 \%$ de los negocios obtienen ganancia hasta de mil córdobas puesto que son negocios que tiene menos variedad de productos, solo es uno y no es muy amplio en lo que se oferta.

\section{Inversiones Realizadas}

En relación con las inversiones que las propietarias realizan a sus negocios, es una ventaja que tienen las mismas, dado que son sujetas del financiamiento crediticio por parte de FUNDEMUJER, amplian el negocio, inverten en materia prima y aumenta de esta forma la clientela.

Las propietarias con los créditos que les ha financiado la Fundación para el Desarrollo de la Mujer FUNDEMUJER, han hecho variación en cuanto a la inversión en el negocios. De 98 mujeres del total de las encuestadas representado por el $47 \%$ aseguran que hacen ampliaciones de inventario como lo es la compra de los productos para venderlos y ofrecerlos, de este modo permite que el negocio cresca satisfactoriamente.

Seguidamente el $48 \%$ afirman que han realizado mejoras en la infraestructura, puesto que desean ampliarlo de manera que las personas se sientan comodas, y de igual forma los que operan dentro del mismo. Un $17 \%$ realizan inversiones en la compra de materiales y equipos como vitrinas, mostradores, refrigeradoras entre otros materiales que son útiles en el negocio para ampliaciones, así mismo un $4 \%$ lo ocupan para realizar otro tipo de compras e inversiones.

\begin{tabular}{|l|l|l|}
\hline Pago de Compras & Frecuencia & Porcentaje \\
\hline Crédito & 46 & $22.55 \%$ \\
\hline Contado & 102 & $50.00 \%$ \\
\hline Ambas & 56 & $27.45 \%$ \\
\hline TOTAL & $\mathbf{2 0 4}$ & $\mathbf{1 0 0} \%$ \\
\hline
\end{tabular}

Cuadro $N^{\circ}$ 7. Pago de compras Universo: 204 encuestas

Fuente: Datos de la Encuesta, Junio 2013 


\section{Efectos Cambiantes}

El total del universo de esta investigación las mujeres encuestadas comentaron que los cambios efectuados para sus negocios después de ser aprobado y hacer las respectivas inversiones al mismo, son positivos, lo que es un resultado muy optimista y ventajoso para los ingresos de estas mujeres microempresarias.

Estas mujeres han hecho un buen uso de su crédito, por tanto FUNDEMUJER juega un papel muy importante en la proyección empresarial de ellas, al otorgar los créditos y dar el debido seguimiento con las capacitaciones para la mejor captación de recursos.

\section{Incidencia del crédito para el desarrollo económico en la familia con enfoque de género.}

En los últimos años se han producido grandes e importantes modificaciones respecto al papel de las mujeres en la sociedad. La esperanza de vida de las mujeres es mayor, aumentan sus niveles de estudios, participan en alta proporción en el mercado del trabajo e incursionan con más éxito en campos antes marcados por el predominio masculino, sin embargo esto se ha traducido en mayor equidad y particularmente en el acceso de las mujeres a los recursos económicos.

Efectivamente, la evidencia muestra que existe un sesgo negativo hacia las mujeres en el acceso a los servicios crediticios como también en las condiciones bajo las cuales lo hacen. Con un análisis de mercado esto ha venido cambiando por que la mujer emplea una mayor proporción de ingresos en su familia.

Se ha demostrado que las mujeres utilizan más de sus ingresos en sus hogares; por lo tanto, cuando a la mujer se le ayuda a aumentar sus ingresos, el bienestar de toda la familia mejora.
El éxito de la mujer beneficia a más de una persona. Se confirma que las mujeres son más propensas que los hombres a gastar sus ganancias en el hogar y necesidades familiares. Por lo que ayudar a la mujer genera un efecto multiplicador que agranda el impacto de las actividades de instituciones financieras como FUNDEMUJER.

El crédito es utilizado para enfrentar situaciones de inestabilidad y desequilibrios internos que permite salir de una situación de dependencia de flujos de corto plazo, flexibilizando así la toma de decisiones estratégicas en un horizonte de tiempo mayor.

Del uso de este crédito se espera obtener una mayor competitividad, mayores ingresos, mayor dinamismo, crecimiento y fuentes de empleo. El crédito entonces, es fundamental en las economías de países como el nuestro, pues ocupa un lugar muy importante en el desarrollo económico. Sin embargo, cuando se trata de generar estabilidad y equilibrio en las mujeres a través del crédito, la realidad es muy distinta. Mas sin embargo el sector financiero como FUNDEMUJER, aplicado particularmente los servicios de crédito, continúa con un enfoque de evaluación basado en características y necesidades de las mujeres, considerando que las distintas realidades y condiciones de trabajo de muchas mujeres se ajustan a los parámetros y esquemas positivos para la obtención de un crédito, por lo que no quedan excluidas si no incorporadas como un potencial de mercado.

\section{Limitantes empresariales para el desarrollo de los negocios de las mujeres}

Normalmente las empresarias de los negocios no tienen establecido un control administrativo en los mismos, esto ocasiona una limitante para el desarrollo de los negocios, porque con el uso de registros contables y administrativos permite una mayor organización, dirección y control y pro del desarrollo de estos. 


\section{Registros Contables}

Según los datos arrojados en las encuestas realizadas a las 204 empresarias, el 55\% del total de las mismas, manifestaron que no llevan un registro contable de los ingresos y egresos de capital de sus negocios. El $45 \%$ de las propietarias encuestadas hacen uso de la aplicación en registros contables puesto que consideran que es más fácil de conocer con cuanto capital cuentan y con cuanto no.

Con los datos arrojados, se puede notar que son 112 empresarias que no hacen uso de los registros contables por diferentes razones, porque no lo consideran importante, no tienen tiempo o no saben cómo aplicarlos. Se presenta un $39.29 \%$ de las mujeres encuestadas y comentan que no saben cómo hacerlo, por ende no llevan un registro contable en el negocio.

Si bien se analiza el nivel académico de las empresarias (ver cuadro 3. Nivel académico) se detalla que solamente el $40 . \%$ de la mujeres encuestadas cursaron primaria y un $4 \%$ no lograron ingresar a una escuela por tal razón, solamente conocen lo básico, por consiguiente se les dificulta poder manejar una contabilidad formal en su negocio.

\begin{tabular}{|l|l|l|}
\hline No Ilevan Registro contable & Frecuencia & Porcentaje \\
\hline No es importante & 21 & $18.75 \%$ \\
\hline No sabe & 44 & $39.29 \%$ \\
\hline No tiene tiempo & 37 & $33.04 \%$ \\
\hline Otros & 10 & $8.92 \%$ \\
\hline TOTAL & $\mathbf{1 1 2}$ & $\mathbf{1 0 0} \%$ \\
\hline
\end{tabular}

Cuadro $\mathrm{N}^{\circ}$ 8. No llevan registros contables Universo: 204 encuestas

Fuente: Datos de la Encuesta, Junio 2013

En esta investigación se proponen cinco estrategias para mejorar el desarrollo económico de los pequeños negocios promovidos por FUNDEMUJER y son:
Estrategia 1: Realización de capacitaciones sobre la importancia de establecer un sistema de registro contable en los negocios.

Estrategia 2: Incorporación en las capacitaciones temáticas de invertir en Publicidad para los negocios

Estrategia 3: Promover el ahorro en las propietarias.

Estrategia 4: Motivar a las empresarias a tener una visión positiva de sus negocios para un futuro.

Estrategia 5: Crear un plan de inversión que permita aprovechar al máximo el crédito en el negocio.

\section{CONCLUSIONES}

Los créditos que otorga la Fundación Para el Desarrollo de la Mujer FUNDEMUJER a las mujeres empresarias de la cuidad de Estelí, les asegura una oportunidad de desarrollo empresarial para las mismas.

Los negocios impulsados por las propietarias que trabajan con créditos otorgados por FUNDEMUJER, actualmente han presentado efectos positivos que hacen que tengan un desarrollo empresarial activo, uno de estos efectos es que las propietarias han aumentado clientela en sus negocios, han generado mayores ganancia presentando un $43 \%$ del total encuestado han podido mejorar la infraestructura del negocio reflejando un $48 \%$ del número de encuestas, esto permite que los clientes y el personal interno del negocio se encuentren en un ambiente amplio para la realización de sus actividades comerciales, además el $48 \%$ indica que el inventario ha aumentado ya que son unas de las inversiones que se han realizado en el negocio.

Por otra parte el $50 \%$ de las propietarias planifican sus compras y las realizan al contado esta es una ventaja puesto que disminuyen los riesgos de tener futuras deudas. 
Además, en algunos negocios se presentan factores que retrasan el crecimiento empresarial y que las mujeres no han implementado en su totalidad, uno de estos, es la poca práctica de utilización de los registros contables de ingresos y egresos del negocios ya que los datos arrojados en las encuestas indican que un $55 \%$ de las mujeres no llevan un registro contable y el escaso refuerzo técnico y financiero representado por un $47 \%$ del total encuestado. La inversión de publicidad, que sirva de cara de presentación del negocio para dar a conocer lo que ellas ofrecen es poca ya que un $31 \%$ de los negocios no tienen ningún tipo de publicidad actualmente.

La hipótesis planteada en este estudio, si se cumplió, ya que la participación de las propietarias en los programas de créditos ejecutados por FUNDEMUJER, han influido satisfactoriamente en el desarrollo económico de los negocios creados por las mismas. El $100 \%$ de las encuestadas del universo de estudio indican que los resultados obtenidos después de ser aprobado el crédito y haciendo las respectivas inversiones para el negocio, los cambios son notorios y positivos puesto que han hecho buen uso del crédito y obteniendo buenos ingresos.

\section{RECOMENDACIONES}

Para que esta investigación sea de utilidad al personal docente y estudiantil de la Facultad Regional Multidisciplinaria, así como personas ajenas a la misma, al personal interno que dirige la Fundación Para el Desarrollo de la Mujer u otro tipo de instituciones financieras y para mujeres que actualmente cuentan con un crédito de la Fundación o que en un futuro solicitaran crédito. Se recomienda:

- Al personal docente y estudiantil de la Facultad Regional Multidisciplinaria que inculquen en los estudiantes el interés por investigar más a fondo sus respectivos temas de investigación y pongan a mayor disposición los documentos que se encuentran en la biblioteca de la facultad para que los estudiantes tengan accesibilidad a la información que se encuentran en las tesis de años anteriores, informes, documentos, etc, y a los estudiantes que tomen en cuenta todo el material disponible.

- A personas ajenas a la Facultad Regional Multidisciplinaria que tomen en cuenta los documentos que se encuentran disponibles en la biblioteca de la misma, siempre y cuando sean temas a fines de tal modo que tengan en estos una fuente confiable de información.

- Al personal interno de la Fundación para el Desarrollo de la Mujer y a diversas instituciones financieras que realicen inspecciones en los negocios de las mujeres para que de esta manera conozcan mejor la situación actual de los negocios, además dar las debidas sugerencias por medio de capacitaciones y que de esta forma las mujeres las incorporen en pro del bienestar propio, del negocio, la familia y del personal de la entidad financiera.

- A las mujeres que cuentan con un crédito de la Fundación, que asistan a las capacitaciones o charlas brindadas por la fundación u otras entidades financieras que se enfocan en promover el desarrollo empresarial y que implementen los conocimientos obtenidos para el desarrollo de sus negocios. A las mujeres que en un futuro solicitaran un crédito, que hagan buen uso del dinero, invirtiendo especialmente en el negocio, planificando las compras y hacerlas preferiblemente de contado para evitar el sobre endeudamiento.

\section{BIBLIOGRAFÍA}

Escalante Morales, Karen Avelina (2010). Administración de Organismos No Gubernamentales sin Fines de Lucro, en los Planes Educativos de la Carrera de Administración de Empresas de FAREM Estelí. Tesis para optar 
al título de Administración de Empresas, Facultad Regional Multidisciplinaria, Estelí, Nicaragua.

Diccionario IBALPE enciclopédico. (Ed). (2005).(6ta ed). Mazatlán, Sinaloa, México: Juan Jesús Ovejero Sanz.

Canales, F; Alvarado, E; Pineda, E. (1998). Metodología de la Investigación, México D.F. (Pág. 163).

Asamblea Nacional de la República de Nicaragua (1992). Ley general sobre personas jurídicas sin fines de lucro. [En Línea]. Consultado [19, Abril 2013] Disponible en: http://legislacion.asamblea. gob.ni

Caffarena Centeno, Leandro. (2009). Situación global de las pymes en Nicaragua. [En línea]. consultado [22, abril, 2004] Disponible en: http://www.cosep. org.ni

Lacayo, J. (1996). MIPYMES en Nicaragua. [En línea].Consultado:[22, abril, 2004] Disponible en: http://www.mific.gob.ni

Castillo, R (2010). Realidad PYME en Nicaragua [En línea].Consultado:[22, abril, 2004] Disponible en: http://jcvalda.wordpress.com

Visita el foro. (2006). Caracterización de Estelí. [versiónelectrónica]. consultado[02, de mayo2013]. Disponible en: http://www.estelienlinea.com.

Asociación Nicaragüense de Instituciones de Microfinanzas (2012). Fundación para el desarrollo de la Mujer (FUNDEMUJER) [En línea]. Consultado: [12,Junio,2013] Disponible en: http:// www.asomif.org

Fondo de Gobernabilidad Democrática (2012). "Inclusión y Empoderamiento Ciudadano de las/ los Jóvenes del Municipio de Condega en el Marco de la Planificación y Gestión Pública”. [En Línea]. Consultado: [20,Junio 2013] Disponible en: http:// www.fondogobernabilidad.org.ni 